\section{Aqui ninguém domina ninguém: sentidos do trabalho e produção de saúde para trabalhadores de assentamento do Movimento dos Trabalhadores Rurais Sem Terra}

\author{
Nobody gives orders here: the meanings of work \\ and health for settlers from the Landless Rural \\ Workers' Movement
}
El significado del trabajo y promoción de la salud para los asentados del Movimiento de Trabajadores Rurales Sin Tierra

\author{
1 Escola Nacional de Saúde \\ Pública Sergio Arouca, \\ Fundação Oswaldo Cruz, \\ Rio de Janeiro, Brasil. \\ 2 Instituto de Pesquisa \\ Clínica Evandro Chagas, \\ Fundação Oswaldo Cruz, \\ Rio de Janeiro, Brasil. \\ Correspondência \\ J. C. B. Santos \\ Escola Nacional de Saúd \\ Pública Sergio Arouca \\ Fundação Oswaldo Cruz. \\ Rua Benjamin Constant 90 \\ apto. 602, Rio de Janeiro, $R J$ \\ 20241-150, Brasil. \\ jcborges83@gmail.com
}

\begin{abstract}
This paper discusses the partial results of qualitative research on lifestyles and meanings attributed to health and work among settlers from the Landless Rural Workers' Movement (MST) and identifies strategies developed by workers to maintain and/or promote health. The study was conducted in a rural settlement affiliated with the MST in Campos dos Goytacazes, Rio de Janeiro State, Brazil. The ergological approach was the main theoretical and methodological reference for understanding work from the perspective of "human activity". The study techniques included document analysis, participant observation, semi-structured interviews, and focus groups, and the data were submitted to thematic content analysis. The landless rural workers attributed the meanings of freedom and satisfaction to their work, associated with self-management and autonomy, which they reported as key elements for health. Although rural work was considered tiring, the work and way of life in the settlement provided this community with possibilities for ensuring their health and resisting the hegemonic agribusiness model.
\end{abstract}

Rural Health; Rural Settlements; Occupational Health
Júlio César Borges dos Santos 1 Élida Azevedo Hennington 2

\section{Resumo}

Este artigo discute os resultados parciais da pesquisa qualitativa que visou a analisar os modos de vida e significados atribuídos por assentados do Movimento dos Trabalhadores Rurais Sem Terra (MST) à saúde e suas relações com o trabalho, e identificar estratégias desenvolvidas pelos trabalhadores para manter elou promover a saúde. O estudo foi realizado em assentamento rural ligado ao MST em Campos dos Goytacazes, Rio de Janeiro, Brasil. A abordagem ergológica constituiu o principal referencial teóricometodológico para compreensão do trabalho na perspectiva de "atividade humana". As técnicas de investigação foram análise documental, observação participante, entrevista semiestruturada e grupo focal, e o tratamento dos dados foi feito por meio de Análise de Conteúdo Temática. Os sem-terra atribuem ao trabalho os sentidos de liberdade e satisfação, positividade esta associada à autogestão e autonomia, referidas como elementos fundamentais para a saúde. Embora considerado desgastante, o trabalho rural e os modos de vida no assentamento configuram para essa comunidade possibilidades de produção de saúde e de resistência ao modelo hegemônico do agronegócio.

Saúde da População Rural; Assentamentos Rurais; Saúde do Trabalhador 


\section{Introdução}

A desigualdade na condição de saúde entre população rural e urbana no Brasil é conhecida pela insuficiente oferta de serviços públicos e de infraestrutura, o que inclui serviços de saúde, saneamento, moradia, transporte, lazer e outros, bem como pela ausência de um modelo de atenção à saúde direcionado para a população rural 1,2. Há proporcionalmente maior necessidade de acesso aos serviços públicos de saúde pela população rural em comparação com a urbana 2,3. Diante dessa situação desigual de cidadania, a população rural constrói cotidianamente estratégias para melhorar suas condições de vida.

Heredia e colaboradores em estudo sobre os impactos regionais dos assentamentos de reforma agrária, considerando os projetos criados no período de 1985 a 1997, observaram que, em relação aos serviços de saúde, havia a presença de agentes de saúde em $78 \%$ dos projetos de assentamento e de postos de saúde em apenas $21 \%$. A maioria dos postos foi instalada por pressão dos assentados, ainda assim raramente havia a presença regular de médicos. Esses aspectos somados aos déficits de outros serviços e de infraestrutura faziam com que os assentados procurassem os serviços de saúde na sede do próprio município, em municípios vizinhos ou cidades que são polos regionais ${ }^{5}$. Pesquisa realizada pelo Instituto Nacional de Colonização e Reforma Agrária (INCRA) em parceria com a Universidade Federal do Rio Grande do Sul, por meio de questionários aplicados à amostra estatística significativa de um universo de 804.867 famílias em 1.164 assentamentos criados no Brasil entre 1985 e 2008, também revelou a dificuldade de atendimento em hospitais e postos de saúde, sendo que $56 \%$ avaliaram negativamente, $23 \%$ consideraram razoável, $1 \%$ não respondeu e apenas $20 \%$ apresentaram avaliação positiva 6 .

A precariedade dos sistemas de captação de água e energia, saneamento, transporte e moradia aparecem como principais limitantes da qualidade de vida nos assentamentos 7,8 . Na pesquisa conduzida pelo Incra, no que se refere ao saneamento, cerca de $1 \%$ das moradias tem acesso à rede de esgoto, enquanto $76 \%$ utilizam fossa e $23 \%$ outras formas de escoamento do esgoto 6 . Consequentemente, doenças como diarreia e infestação parasitária têm sido recorrentes nos estudos de saúde da população assentada 9,10,11,12. Outro grave problema que afeta os trabalhadores rurais - do agronegócio, sem terra e agricultores familiares é a exposição aos agrotóxicos 13,14,15. Em 2008, a exposição média foi de 3,9 litros por habitante, passando para 4,3 litros/habitante em 2010. Entre 2007 e 2011, foram registrados 12.924 intoxicações por agrotóxicos na agricultura, perfazendo $41 \%$ do total de registros por este agravo ${ }^{6}$.

Há pesquisas que relacionam uma melhor percepção de saúde à inserção no Movimento dos Trabalhadores Rurais Sem Terra (MST) e à conquista da posse da terra, educação, renda e segurança alimentar e também de saúde 16,17,18. O MST, principal movimento social do campo no Brasil e um dos mais importantes no mundo, foi criado em 1984 e está presente em 23 estados brasileiros e no Distrito Federal, organizando mais de 1,5 milhão de pessoas 19,20,21. Os objetivos colocados pelo movimento são a luta pela terra, pela reforma agrária e por uma sociedade mais justa e fraterna. Nos acampamentos e assentamentos rurais onde atua, o MST busca construir um modo de vida e trabalho que se aproxima da agricultura camponesa cujos valores, costumes, economia e relação com a natureza expressam um modo diferenciado de fazer agricultura, de resistência ao modelo hegemônico do agronegócio, com fortes laços comunitários, baseada no trabalho familiar em pequenas propriedades e produção diversificada para comercialização e também autoconsumo 22,23.

O MST considera uma concepção de saúde abrangente, que envolve a relação indivíduo-sociedade-natureza, valorizando a organização política, a preservação ambiental, as práticas de saúde populares e a medicina tradicional. Com isso, busca incentivar alternativas próprias de enfrentamento dos problemas de saúde, ao mesmo tempo em que preza pelos princípios organizadores do Sistema Único de Saúde (SUS) 24.

No Brasil, ainda são poucas as pesquisas da área da saúde com enfoque na população rural, movimentos sociais e modelos produtivos no campo. Este artigo apresenta resultados parciais da pesquisa cujo foco foi analisar os modos de vida e significados atribuídos por assentados do MST à saúde e suas relações com o trabalho, em confronto às concepções e prescrições do movimento, e identificar as estratégias desenvolvidas pelos trabalhadores para manter e/ou promover a saúde. Partimos do pressuposto de que a relação com o MST confere determinada identidade ao grupo de assentados, que repercute na maneira de organização política e social do assentamento e nos processos de trabalho, e traz consequências positivas à saúde dessa população. Este estudo permitiu aprofundar o conhecimento das condições sociais e de saúde de agricultores familiares camponeses e favoreceu a compreensão do cotidiano de vida e trabalho em assentamento rural e suas renormatizações, evidenciando desafios das políticas públicas voltadas para a população do campo. 


\section{Percurso metodológico}

Para a Ergologia, na realização do trabalho existe uma tensão entre o prescrito que se apresenta sob um determinado contexto e o que acontece na atividade, o trabalho real. Diante do prescrito, o trabalhador articula sua experiência, valores e desejos renormatizando o trabalho para melhor realizá-lo e nele se realizar. A perspectiva ergológica propõe conhecer o trabalho aproximando-se dele para compreender as variabilidades e singularidades estabelecidas diante do encontro entre o trabalhador e o imponderável da atividade, considerando a interação entre três polos: o polo conceitual, o dos saberes dos trabalhadores e articulados pelo polo ético-epistemológico 25 .

O trabalho compreende a dimensão objetiva da ação e também subjetiva. Por um lado, existe como objeto social e real constituído de um certo número de exigências econômicas, técnicas, físicas e jurídicas, mas existe também como objeto do desejo, o que remete ao modo de ser do sujeito, sua identidade pessoal e social, sua maneira de se relacionar com o outro e com o mundo 26. Assim, trabalho e modos de vida estão imbricados, especialmente quando se considera a sociedade rural camponesa, na qual produção e reprodução social se dão no mesmo tempo e território.

A renormatização no trabalho se dá a partir de um debate de normas e valores, nas "brechas de normas". As escolhas e ações constituem os "usos de si" que o trabalhador faz: "usos de si por si", na busca de construir a situação mais adequada para ele próprio, e "usos de si por outros", que são as gerencias externas ao trabalhador, que ocorrem fora de sua governabilidade, mas que refletem as condições políticas, econômicas, sociais e técnicas em que se realiza a atividade 27 .

\section{Lócus de pesquisa, sujeitos, técnicas} de produção e análise dos dados

Utilizamos a triangulação de técnicas na produção de dados 28 , articulando pesquisa documental, observação participante, entrevistas semiestruturadas e grupo focal.

A pesquisa documental foi realizada com base no acervo sobre o MST do Centro de Documentação da Universidade Estadual Paulista. Foram selecionados 35 documentos referentes ao período de 1990 a 2008, cujos conteúdos apresentavam informações sobre práticas, orientações e estratégias de saúde, trabalho e ambiente, além de documentos disponíveis na página do MST na internet e na sede da coordenação estadual no Rio de Janeiro, Brasil. Essas foram as prescrições que buscamos confrontar, num segundo momento, com os modos de vida e trabalho no assentamento.
A escolha do assentamento rural a ser estudado obedeceu aos seguintes critérios: (1) pertencer ao MST e estar localizado no Estado do Rio de Janeiro; (2) que os trabalhadores tivessem a posse da terra há pelo menos cinco anos; (3) onde fossem desenvolvidas atividades produtivas locais; (4) que houvesse autorização do MST e dos coordenadores do assentamento para a realização da pesquisa. O assentamento Dandara dos Palmares, localizado na região norte do Estado do Rio de Janeiro, atendeu a todos os critérios.

Foram 21 dias de estadia no assentamento e completa imersão no campo, divididos em dois momentos entre outubro e novembro de 2010. Nos primeiros 15 dias o cotidiano dos trabalhadores foi acompanhado, identificando-se as características gerais de vida, arranjos familiares, tipos de trabalho, lazer e formas de organização comunitária. Além da observação participante, esse período permitiu identificar os potenciais sujeitos de pesquisa e dar continuidade ao trabalho de campo.

Os pré-requisitos para escolha dos participantes da pesquisa foram: ter acima de 18 anos de idade, residir no local há mais de cinco anos e aceitar participar do estudo. A seleção dos sujeitos priorizou aqueles considerados informantes-chave, ou seja, pessoas com conhecimento a respeito dos temas abordados e/ou que, por sua inserção eram representativos do pensamento da comunidade. Fizeram parte da amostra diferentes tipos de representação local - líderes políticos e comunitários, trabalhadores com histórico de assalariamento, trabalhadores com conhecimento sobre o uso de plantas medicinais e legitimidade comunitária para falar sobre saúde. Ademais, selecionamos alguns representantes dos assentados que desenvolviam atividades majoritariamente no assentamento e outros cujo trabalho estava caracterizado essencialmente pelo assalariamento no campo, fora do assentamento. Buscou-se um equilíbrio de gênero, entretanto houve menor participação das mulheres, fato que pode estar relacionado a questões de gênero existentes na sociedade em geral e bastante marcadas no meio rural, incluindo a invisibilidade do trabalho feminino e a posição subalterna e de opressão, em que o homem tem quase sempre a prerrogativa da fala 29 .

Foram realizadas 11 entrevistas semiestruturadas, com oito homens e três mulheres, e um grupo focal com seis trabalhadores e duas trabalhadoras do assentamento. Para diferenciar as falas, os trabalhadores(as) foram identificados como Liderança em Saúde, Coordenador, Trabalhador Comum, seguidos de um número de acordo com o sujeito de pesquisa. A Análise de Conteúdo na vertente temática proposta por Minayo 30 foi utilizada, buscando-se compreender os significados que os sujeitos atribuem à realidade e às relações 
entre saúde e trabalho baseando-se nas seguintes categorias: "autonomia", "renormatização", "trabalho e saúde". O material das entrevistas e grupo focal foi transcrito, submetido à leitura exaustiva até que houvesse clareza do conteúdo; em seguida foram levantados os temas convergentes e divergentes, possibilitando a identificação das unidades de sentido. As categorias "renormatização" e "trabalho e saúde" foram previamente estabelecidas, sendo a primeira com base nos pressupostos do referencial ergológico, enquanto "autonomia" surgiu como categoria empírica. Por fim, as categorias e temas foram confrontados na análise dos documentos e observações de campo, também submetidos aos mesmos procedimentos.

\section{Resultados e discussão}

\section{Caracterização do assentamento Dandara dos Palmares}

O assentamento Dandara dos Palmares está localizado no Município de Campos dos Goytacazes, região norte fluminense, tradicionalmente marcada por sua importância agrícola no estado. A história do município está intimamente relacionada ao desenvolvimento da economia açucareira na região. Mesmo após o colapso desse setor, no final dos anos 1980, a cidade ainda abrigava 15 usinas de açúcar e álcool que exploravam 185 mil hectares com monocultura de cana-de-açúcar 31 .

A população correspondia a 463.731 habitantes, sendo cerca de $90 \%$ residentes na área urbana e $10 \%$ na área rural (Instituto Brasileiro de Geografia e Estatística. Censo 2010. http://www.censo2010. ibge.gov.br, acessado em 20/Abr/2012). Os dados de ocupação e uso da terra mostram uma elevada concentração fundiária, onde $78 \%$ dos 8.098 estabelecimentos rurais eram de agricultura familiar e ocupavam $17,5 \%$ da área produtiva, enquanto a agricultura patronal representava $22 \%$ dos estabelecimentos ocupando $82,5 \%$ da área produtiva (IBGE. Censo agropecuário, 2006. http://www. ibge.gov.br/home/estatistica/economia/agrope cuaria/censoagro/default.shtm, acessado em 30/ Mar/2012).

O termo assentamento compreende uma unidade de produção agrícola criada por determinação do poder público e judiciário, sendo local de moradia e trabalho dos assentados, portanto, território primordial de construção das redes sociais, identidades e pertencimento, onde se processam mudanças nas posições sociais e de poder cujos desdobramentos conformam um padrão de sociabilidade 33,34 .

$\mathrm{O}$ assentamento Dandara dos Palmares surgiu a partir da mobilização de 30 famílias sem-terra organizadas junto ao MST, que ocuparam a Fazenda Santana do Betel em 2003. Atualmente, 21 famílias num total de aproximadamente 75 pessoas vivem em Dandara, existindo uma população de crianças e adolescentes bastante expressiva (40\% entre 6 e 18 anos) e equilíbrio de gênero. A relação com o MST diminuiu alguns anos após o assentamento, embora mantivessem proximidade política e recebessem assistência de técnicos do movimento. No assentamento todos participam do trabalho, seja nas atividades produtivas, domésticas ou políticas, porém as crianças e jovens se ocupam mais com os estudos e os adultos com o trabalho rural, quase sempre combinando o trabalho no próprio assentamento com outros para fazendeiros próximos.

Heteronomia versus autonomia: trabalhar para si, trabalhar para outro

O MST reconhece o trabalho como o meio encontrado pelos indivíduos em sociedade para realizar suas necessidades humanas, desde aquelas que compõem a dimensão da sobrevivência até as necessidades complexas constitutivas da subjetividade - desejos, motivações, projetos de vida dos trabalhadores. Com base nesses pressupostos, valoriza-se a solidariedade e cooperação e o fomento de uma forma de organização da vida e do trabalho oposta à maximização individual-racionalista da ordem capitalista 35,36 . Nesse sentido, a cooperação e o trabalho coletivo são orientações fundantes para o MST, que busca romper com as formas de trabalho assalariado.

Os assentados tendem a diferenciar o caráter mais autônomo do trabalho no assentamento, "trabalhar para si", em oposição ao trabalho assalariado em fazendas do entorno do assentamento ou na cidade, "trabalhar para o outro". Verifica-se no "trabalhar para o outro" a alternativa encontrada para suprir as necessidades de sobrevivência e consumo dos camponeses, que se veem forçados a buscar no trabalho assalariado a compensação da falta de incentivos políticos e econômicos para sua produção ${ }^{37}$. Remete, ainda, à alienação de si, do sujeito submetido às regras mais ou menos rígidas de obediência, hierarquia e controle, e também à mais valia do trabalho e lucro de outro em detrimento de sua saúde.

Por outro lado, a concepção do "trabalhar para si” alcança outras dimensões da necessidade humana, pois permite ao assentado fazer-se valer como sujeito que tem necessidades e desejos. A maior autonomia nesse caso possibilita as escolhas "do que se fazer" e "como fazer" o trabalho, ao mesmo tempo em que garante o retorno mais justo pelo produto realizado. 
Trabalhador 1: "Pra mim, aqui a gente tem saúde. É, porque dentro da cidade você acorda pros outros (...) e aqui não. Aqui não tem quem manda, não tem quem fala nada, você acorda e tanto faz você sair sem trabalhar ou não. Aqui se você precisa ficar uma semana em casa você fica. Você trabalha pra você. Você vive pra você. (...) Aqui ninguém manda em ninguém, aqui ninguém domina ninguém. A dia [trabalho de diarista no campo] é assim, o cara não tem muita escolha não, ele tem que trabalhar, né?".

Trabalhador 2: "Mas faz mal. Faz mal. Prejudica a saúde da pessoa, nem todo mundo tem a mesma saúde. Às vezes sobe a pressão, ou outro problema, se pegar aquele volta do sol todinha, nem todo mundo tem a mesma saúde. (...) Porque você trabalhar a dia pra beneficia outro e chegar no final do mês não sobrar nada pra ele, desanima. Agora o cara tendo o lote dele não, se ele trabalhar e produzir sempre tem (...) uma roça, tem um animal. Agora a pessoa que vive na cidade tem o quê? Só tem a moradia e não tem mais nada não".

Fica evidente a correlação entre os valores do trabalho para os assentados e os valores da organização social proposta pelo MST, que se articula na realização de um projeto de sociedade no nível local 38,39. Por outro lado, alguns trabalhadores realizavam atividade assalariada fora do assentamento para suprir as limitações materiais, econômicas ou a falta de assistência técnica adequada. Isso evidencia o conflito quanto às práticas de trabalho e reafirma um debate de normas e valores que procura equacionar o possível e o desejável. Tem-se a obrigação e a subordinação do trabalho assalariado ante a autonomia e liberdade do trabalho no assentamento, sempre tensionado pelas imposições macroeconômicas e sociais.

Nesse caso, a motivação para o trabalho pode ser considerada com base em três perspectivas: a realização do que é preciso para "viver materialmente"; a "dimensão do ser", do reconhecimento de si no trabalho, na posição que ocupa; e o "ser com os outros" que corresponde a reconstruir o mundo a partir dos valores que partilha com sua comunidade 25 . Observamos que o "trabalho para si” agrega essas três dimensões enquanto o "trabalhar para o outro" está restrito à primeira dimensão na concepção dos assentados. Portanto, os valores de bem comum identificados nas orientações do MST para o trabalho coletivo e o protagonismo dos trabalhadores na organização de um modelo de sociedade que se opõe à ordem econômica vigente estão presentes nos sentidos atribuídos pelos assentados ao trabalho, notando-se distinções entre uma relação de trabalho assalariada ou autogestionada.
Problemas de saúde relacionados ao trabalho rural

De modo geral, os principais problemas de saúde referidos pelos trabalhadores incluíam a excessiva exposição à radiação solar, dores musculares e esgotamento físico decorrente do trabalho pesado, e risco de intoxicação por agrotóxicos. No trabalho fora do assentamento, o desgaste, principalmente no corte de cana, e a aplicação de agrotóxicos aparecem como os principais problemas de saúde. Com relação ao trabalho no assentamento, o uso de agrotóxicos e a exposição ao sol e intempéries são enfatizados pelos assentados.

No corte da cana, por exemplo, destacam-se fatores ergonômicos, físicos e químicos afetando a saúde do trabalhador devido ao ritmo intenso e acelerado dos movimentos braçais, postura inadequada do corpo por longos períodos, reduzido período de descanso, exposição aos agrotóxicos, radiação solar e acidentes com equipamentos cortantes e com animais peçonhentos. A jornada de trabalho assalariado no campo com prescrições rígidas de horários e tarefas limita a possibilidade do trabalhador de atuar sobre os fatores que afetam a sua saúde, pois a mudança nestes padrões quase sempre resulta em menor produtividade e repreensão por parte dos contratantes. Em relação à aplicação de agrotóxicos - risco à saúde e cumprimento a normas de proteção - observamos contradições entre as escolhas e motivações dos trabalhadores e seu conhecimento e percepção sobre os riscos, de modo que o trabalhador deixa de lado a saúde para alcançar metas de produção.

A utilização de agrotóxicos é uma prática comum entre assentados, principalmente os que possuem mais recursos financeiros para arcar com o alto custo dos produtos. Há um conjunto de fatores que facilita e orienta os agricultores a adotar o modelo tradicional de produção, pois o mercado convencional exige a padronização da mercadoria e remunera melhor este tipo de produto; os canais de venda já estão estabelecidos na região e os compradores mais acessíveis (geralmente atravessadores). Também existe a ideia de que com os agrotóxicos alcança-se mais "lucro" com menos desgaste físico. No entanto, os trabalhadores reconhecem que esse modo de produzir prejudica a saúde individual, da comunidade e do ambiente em geral, mas diante do custo de subverter as normas antecedentes macrossociais e econômicas, procuram adequar-se a elas e transgredi-las na medida do possível.

Liderança Saúde 1: "A terra foi feita pra enxada, não para o veneno, mas com a tecnologia 
agora, não tem como produzir, não dá pra fazer com a enxada".

Coordenador 1: "Na hora de plantar você pensa: vou plantar, mas vou vender pra quem? (...) Então, às vezes o agricultor se submete à agricultura tradicional, que é a da cana, do abacaxi, que é do atravessador pra agroindústria mais próxima que tem, né? (...) ele não vai sair da cana, do abacaxi ou do gado pra tocar uma hortaliça, uma outra agricultura que ele nunca lidou (...). Dificulta até mesmo a mudança de cultura dos agricultores. Precisa de um projeto mais assistido mesmo pra desenvolver isso".

O MST questiona o uso de agrotóxicos e incentiva a agroecologia, conforme registrado na Carta do seu último Congresso Nacional 9,40. Entretanto, a produção agroecológica é colocada em prática no assentamento apenas quando se refere à produção para o autoconsumo familiar, ou seja, opondo-se às regras do mercado. Vemos que dependendo da finalidade a qual se destina o produto, este pode ser produzido sob diferentes prescrições que se reestruturam por significados e sentidos distintos 41. Evidenciou-se no assentamento a coexistência de um trabalho orientado pelo modelo hegemônico capitalista e outro de acordo com o ideário do MST.

Na realização da atividade, no trabalho assalariado, as normas de subordinação, a hierarquia das relações e o controle sobre o ritmo, intensidade e modo de fazer o trabalho interpelam o trabalhador a fazer uso de si em sentido contrário às suas escolhas, "uso de si por outros", num movimento de subordinação ao capital. No assentamento, o que ocorre é uma diferenciação nessa relação de tal modo que a autogestão da atividade e a maior autonomia do trabalhador não eliminam os constrangimentos e imposições macrossociais, mas permitem a ele explorar efetivamente a dimensão do "uso de si", de acordo com as suas motivações, desejos e escolhas.

Estratégias para produzir e promover a saúde no assentamento

Para o MST a saúde é concebida de maneira ampliada e diretamente relacionada às condições gerais de vida, e dialoga com as proposições da Organização Mundial da Saúde e do Sistema Único de Saúde (SUS), mas carrega também componentes próprios referentes à realidade do campo e, em particular, dos assentamentos e acampamentos rurais ${ }^{42}$. Em relação à "organização política interna" no assentamento proposta pelo MST, esta corresponde à estratégia de "luta por saúde" por meio da conscientização dos trabalhadores para a necessidade de se organizarem coletivamente e reivindicar do Estado a efetividade de uma política de saúde pública conforme determina a Constituição 43,44 . O Movimento orienta também práticas populares de saúde, principalmente o uso de plantas medicinais e a medicina tradicional.

Problemas de acesso aos serviços de saúde foram destacados pelos assentados nas entrevistas que referiram a necessidade de deslocamento até a cidade vizinha de São Francisco de Itabapoana, ou Campos dos Goytacazes, onde se concentra a oferta destes serviços, além da falta de atendimento sendo, por vezes, necessário pernoitar na fila para conseguir senha. Para suprir a dificuldade de deslocamento, os assentados, inicialmente reivindicaram à prefeitura o direito de utilizarem o serviço de transporte escolar que circula dentro do assentamento, porém, não sendo suficiente, decidiram pelo uso de um carro comunitário para o transporte de quem precisasse de atendimento médico em situações de emergência.

Trabalhador 3: "No hospital do ponto mesmo, pra você conseguir marcar uma consulta você tem que chegar duas horas da manhã um dia antes, pra conseguir a ficha pro outro dia. (...) Aqui se passar mal de repente, se não tiver uma moto, ou se tiver sozinho e não puder ir de moto, como é que faz?".

Liderança Saúde 2: "O que nós precisamos demais é um posto de saúde, entendeu? (...) Que é a necessidade não só da gente adulto, é das crianças que diariamente tão gripadas, né? Alguma coisa que às vezes aparece que a gente não sabe, uma coceira... e a gente vai passando remédio caseiro, vai levando".

Trabalhador 3: "[O Agente Comunitário de Saúde] veio pra fazer cadastro [do cartão] do SUS (...) marcar consulta que precisava ele não marca, só vem pra pergunta e não pode fazer mais nada".

Foi relatado que a Estratégia Saúde da Família realizou em média duas visitas por semestre para atender as 21 famílias do assentamento e outras que vivem na região, sendo esta frequência insuficiente para dar conta da demanda, o que deixa os trabalhadores em condições pouco favoráveis para o acompanhamento de sua saúde. Em Floresta, distrito de São Francisco de Itabapoana, há um posto de saúde que atende a população rural do entorno, mas com poucos recursos de atendimento e falta de médicos, de acordo com o relato dos trabalhadores. Segundo o agente comunitário de saúde (ACS) responsável pelo assentamento, seu trabalho se concentra na atenção às crianças e gestantes e nas visitas. Os assentados reivindicaram às Secretarias Municipal e Estadual de Saúde a organização de um posto no assentamento para receber os profissionais de saúde ao menos uma vez por mês, a fim de suprir em parte a demanda da comu- 
nidade, incluindo atividades de educação em saúde. Ofereceram inclusive a estrutura da casa sede do assentamento, porém não obtiveram sucesso. Esses aspectos da organização interna revelam tanto a precariedade do acesso aos serviços de saúde quanto a iniciativa política e comunitária de reverter a situação interpelando o poder público e/ou implementando iniciativas próprias.

No assentamento o uso de plantas medicinais ocorria, porém, de forma individual ou por núcleo familiar, por meio de horta própria ou retirada de plantas nativas, não havendo uma estratégia coletiva de organização destas práticas de saúde. Assim, os assentados que detinham conhecimento sobre o assunto eram consultados pelos outros quando necessitavam, persistindo o uso de fitoterapia mesmo quando se pretendia o atendimento tradicional pelo SUS.

Liderança Saúde 2: "Faz um chá pra ver se resolve. Essa é a primeira coisa, né? Se não dá certo tem que sair pra fora, tem que procurar um posto de saúde, um médico, é contar com a sorte. Porque também não é fácil. Mas é isso, primeiro é isso, faz um chá, um xarope... teve uma época que tinha o pessoal da saúde fazendo umas pomadas também".

Equipamentos de proteção individual (EPI) eram utilizados na lavoura contra a intoxicação por agrotóxicos, mas reduziam ao uso de máscaras, botas e roupas compridas, reservadas para a aplicação dos produtos. No entanto, ressaltamos que os assentados apontam a dificuldade de utilizarem os EPI indicados, inclusive as máscaras, por serem inapropriadas para o serviço, pois dificultam os movimentos do corpo, provocam dificuldade de respiração e produzem uma sensação de desconforto devido ao calor, o que aponta para a inadequação das normas de segurança elaboradas à distância do processo de trabalho 45 .

Trabalhador 4: "É muito difícil a aplicação do veneno. No início minhas costas doía tudo no final do dia, de carregar a bomba [costal], meus pés ficaram tudo rachado porque eu não conseguia trabalhar com as botas, me segurava muito, coçava tudo, nunca fui de ter calçado. (...) No dia de sol.. usar máscara é sofrimento que só!".

Na tentativa de reduzir os efeitos negativos para a saúde, os trabalhadores controlam o tempo de trabalho fracionando as aplicações e evitando os dias de ventania e calor intenso ou reduzem a exposição ao sol no período de maior incidência de radiação.

Trabalhador 5: "A vantagem de trabalhar no assentamento é que geralmente você tem a chance de folgar as horas de sol, né? E se trabalha o dia a dia pra fazendeiro geralmente só tem direito de parar às 4 horas [16 horas]. Você não pode para, tanto faz o sol tá quente ou o sol tá frio ou tá chovendo, o cara não pode parar que é dia de serviço dele".

Essas práticas, ainda que não sejam corretas ou suficientes para eliminar o efeito nocivo dos agentes, representam efetivamente uma tentativa de proteção que somente pode ser colocada em prática quando os trabalhadores possuem algum nível de autonomia para organizar o próprio trabalho.

Desvelar a sutileza entre o fazer dos sujeitos no aqui e agora e as estruturas e relações sociais que condicionam a atividade é o desafio proposto pela perspectiva ergológica. Desse modo, a compreensão da situação de trabalho se dá a partir da articulação e do diálogo entre os saberes disciplinares e a experiência dos trabalhadores produzindo encontros e novos saberes que devem ser apreciados sempre baseando-se em uma posição de humildade epistemológica, num movimento dialético entre o macro e a micropolítica, reconhecendo a atividade como espaço de microtransgressões e rupturas 46,47 .

\section{Considerações finais}

De modo geral, as condições de saneamento, transporte, moradia e acesso aos serviços de saúde no assentamento constituem fatores estruturais distantes dos padrões considerados propícios a uma condição de vida saudável. As recentes iniciativas como a Política Nacional de Saúde do Trabalhador, a inclusão dos assentados no Programa Nacional de Habitação Rural e a discussão acerca da Política Nacional de Saúde Integral das Populações do Campo e da Floresta indicam a inserção destas questões na agenda política e abrem possibilidades de melhoria da qualidade de vida da população do campo.

No assentamento Dandara dos Palmares, o conflito entre o modelo do agronegócio em oposição à agroecologia e a proteção à saúde humana e ambiental estava mediado pelas possibilidades e escolhas individuais (uso de si por si), levando em conta valores, princípios e desejos, mas também pelos agenciamentos macropolíticos e econômicos (usos de si por outros) que de alguma forma antecipam e determinam maneiras de realizar o trabalho. Ressaltamos ainda que essa contradição traz para a agenda a questão do agrotóxico como pacote tecnológico adequado às exigências econômicas do atual modelo de produção, mas que não responde necessariamente às demandas e desejos complexos da sociedade em relação a outras dimensões como saúde, trabalho e justiça ambiental. 
Entre a perspectiva de sociedade proposta pelo MST e os ditames do agronegócio, no cruzamento desses dois projetos, impõe-se uma "dramática”. E, nesse espaço, muitas vezes paradoxal e contraditório, habitam os sentidos que os assentados atribuem ao trabalho e à saúde. Assim pode-se compreender por que o trabalho rural fora do assentamento foi lembrado pelos sujeitos por ser exaustivo e penoso principalmente quando vinculado ao modo de organização e às formas precárias de contratação e assalariamento, enquanto o trabalho no próprio lote é reconhecido por minimizar este desgaste, pela maior autonomia na sua organização e realização.

\section{Resumen}

Este artículo discute los resultados de un estudio que tuvo como objetivo examinar los modos de vida y los significados de la salud, atribuidos a los trabajadores rurales del Movimiento de los Trabajadores Rurales Sin Tierra (MST) y su relación con el trabajo, e identificar las estrategias desarrolladas para mantener y/o promover la salud. El estudio se realizó en un asentamiento rural del MST en Campos dos Goytacazes, Río de Janeiro, Brasil. La ergología era el principal marco teórico y metodológico. Las técnicas de investigación fueron el análisis documental, observación participante, entrevistas semiestructuradas y grupos de discusión. El análisis de los datos se realizó mediante el análisis de contenido temático. Los trabajadores sin tierra se adhieren a los sentimientos de libertad y satisfacción. La positividad está asociada con la autogestión y la autonomía como la clave para la salud. Pese a que se considera un trabajo estresante, trabajo y vida rurales en el asentamiento significan para esta comunidad un potencial en la producción de salud y resistencia a las prescripciones impuestas por el modelo hegemónico de la agroindustria.

Salud Rural; Asentamientos Rurales; Salud Laboral
Solidariedade, liberdade e autonomia são elementos presentes nos discursos e na prática como possibilidade de produção de saúde e de realizar o trabalho no campo de modo mais favorável aos interesses do trabalhador, reafirmando a proposição de que todo trabalho é sempre "uso", e também demonstrando a relevância e o desafio da construção de políticas públicas de saúde para os trabalhadores rurais que consideram e preservam seus desejos, necessidades e modos de vida.

\section{Colaboradores}

J. C. B. Santos trabalhou na concepção, metodologia de pesquisa, produção e análise dos dados e redação do artigo. É. A. Hennington participou em todas as fases do trabalho orientando a produção e revisando o artigo.

\section{Agradecimentos}

Aos trabalhadores e trabalhadoras do assentamento Dandara dos Palmares e ao Movimento dos Trabalhadores Rurais Sem Terra. 


\section{Referências}

1. Travassos C, Viacava F. Acesso e uso de serviços de saúde em idosos residentes em áreas rurais, Brasil, 1998-2003. Cad Saúde Pública 2007; 23:2490-502.

2. Sichieri R, Moura AS, Godoy JL, Niero N, Matsumoto FN. Estado nutricional de crianças e relações de trabalho da família em uma comunidade rural do Paraná, Brasil. Cad Saúde Pública 1993; 9:28-35.

3. Kassouf AL. Acesso aos serviços de saúde nas áreas urbana e rural do Brasil. Revista de Economia e Sociologia Rural 2005; 43:29-44.

4. Núcleo de Estudos Agrários e Desenvolvimento Rural, Departamento Intersindical de Estatística e Estudos Socio-econômicos, Ministério do Desenvolvimento Agrário. Estatísticas do meio rural 2010/2011. São Paulo: Ministério do Desenvolvimento Agrário; 2011.

5. Heredia B, Medeiros L, Palmeira M, Cintrão R, Leite SP. Análise dos impactos regionais da reforma agrária no Brasil. Estudos Sociedade e Agricultura 2002; (18):73-111.

6. Instituto Nacional de Colonização e Reforma Agrária. Pesquisa sobre a qualidade de vida, produção e renda dos assentamentos da reforma agrária, 2010 (primeiros resultados). http://www.incra.gov. br (acessado em 15/Mai/2011).

7. Soares D. "O sonho de Rose": políticas de saúde pública em assentamentos rurais. Saúde Soc 2006; 15:57-73.

8. Carneiro FF. A saúde no campo: das políticas oficiais à experiência do MST e de famílias de "bóias-frias" em Unaí, MG, 2005 [Tese de Doutorado]. Belo Horizonte: Universidade Federal de Minas Gerais; 2007.

9. Castro TG, Campos FM, Priore SE, Coelho FMG, Campos MTFS, Franceschini SCC, et al. Saúde e nutrição de crianças de 0 a 60 meses de um assentamento de reforma agrária, Vale do Rio Doce, MG, Brasil. Rev Nutr 2004; 17:167-76.

10. Ferreira SH, Albuquerque MFM, Ataide TR, Morais MGC, Mendes MCR, Siqueira TCA, et al. Estado nutricional de crianças menores de dez anos residentes em invasão do "Movimento dos Sem-Terra”, Porto Calvo, Alagoas. Cad Saúde Pública 1997; 13:137-9.

11. Ferreira P, Lima MR, Oliveira FB, Pereira MLM, Ramos LBM, Marçal MG, et al. Ocorrência de parasitas e comensais intestinais em crianças de escola localizada em assentamento de sem-terras em Campo Florido/MG, Brasil. Rev Soc Bras Med Trop 2003; 36:109-11.

12. Souza EA, Silva-Nunes M, Malafronte RS, Muniz PT, Cardoso MA, Ferreira UM. Prevalence and spatial distribution of intestinal parasitic infections in a rural Amazonian settlement, Acre State, Brazil. Cad Saúde Pública 2007; 23:427-34.

13. Carneiro FF, Pignati W, Rigotto RM, Augusto LGS, Rizollo A, Muller NM, et al. Dossiê ABRASCO: um alerta sobre os impactos dos agrotóxicos na saúde. Rio de Janeiro: ABRASCO; 2012.

14. Peres F, Moreira JC. Saúde e ambiente em sua relação com o consumo de agrotóxicos em um pólo agrícola do Estado do Rio de Janeiro, Brasil. Cad Saúde Pública 2007; Suppl 4:S612-21.
15. Rigotto R, organizador. Agrotóxicos, trabalho e saúde: vulnerabilidade e resistência no contexto da modernização agrícola no Baixo Jaguaribe/PE. Fortale za: Edições UFC; 2011.

16. Cimbleris A. Utilização de plantas medicinais no assentamento Ho Chi Minh (MG), do MST: pesquisa-ação [Dissertação de Mestrado]. Belo Horizonte: Universidade Federal de Minas Gerais; 2007.

17. Gaia MCM. Saúde como prática da liberdade: as práticas de famílias em um acampamento do MST e o desenvolvimento de estratégias de educação popular em saúde [Dissertação de Mestrado]. Belo Horizonte: Centro de Pesquisa René Rachou, Fundação Oswaldo Cruz; 2005.

18. Guedes FVNL. Condições, modo de vida e renda no assentamento liberdade, Periquito - MG: fundamentação para a epidemiologia social [Dissertação de Mestrado]. Belo Horizonte: Universidade Federal de Minas Gerais; 2006.

19. Morissawa M. A história da luta pela terra e o MST. São Paulo: Expressão Popular; 2001.

20. Movimento dos Trabalhadores Rurais Sem Terra. Entenda como estamos organizados. http://www. mst.org.br/taxonomy/term/330 (acessado em 06/ Set/2009).

21. Fernandes BM. Formação territorial do MST no Brasil. In: Carter M, organizador. Combatendo a desigualdade social: o MST e a reforma agrária no Brasil. São Paulo: Editora Unesp; 2010. p. 161-98.

22. Ploeg JDVD. Camponeses e impérios alimentares: lutas por autonomia e sustentabilidade na era da globalização. Porto Alegre: Editora UFRGS; 2008.

23. Sabourin E. Camponeses do Brasil: entre a troca mercantil e a reciprocidade. Rio de Janeiro: Editora Garamond; 2009.

24. Movimento dos Trabalhadores Rurais Sem Terra. Boletim informativo. Brasília: Coletivo Nacional de Saúde; 2007.

25. Schwartz Y, Durrive L, organizadores. Trabalho \& ergologia: conversas sobre a atividade humana. Rio de Janeiro: EdUFF; 2007.

26. Revuz C. O trabalho e o sujeito. In: Schwartz Y, Durrive L, organizadores. Trabalho \& ergologia: conversas sobre a atividade humana. Rio de Janeiro: EdUFF 2007. p. 226-45.

27. Durrive L, Schwartz Y. Glossário da ergologia. Laboreal 2008; 4:23-8.

28. Thurmond VA. The point of triangulation. Journal of Nursing Scholarship 2001; 33:253-57.

29. Silva CB. Relações de gênero e subjetividades no devir do MST. Revista Estudos Feministas 2004; 12:268-87.

30. Bardin L. Análise de conteúdo. Lisboa: Edições 70; 2010

31. Minayo MCS. Fase de análise do material qualitativo. In: Minayo MCS, organizadora. O desafio do conhecimento: pesquisa qualitativa em saúde. 11a Ed. São Paulo: Editora Hucitec; 2008. p. 299-384.

32. Souza PM, Ponciano NJ, Mata HTC. Estrutura fundiária das regiões Norte e Noroeste do Estado do Rio de Janeiro: 1972 a 1998. Revista de Economia e Sociologia Rural 2007; 45:71-91.

33. Bergamasco SM, Norder LAC. Assentamentos rurais. São Paulo: Editora Brasiliense; 1998. 
34. Neves DP. Assentamento rural: confluência de formas de inserção social. Estudos, Sociedade e Agricultura 1999; 13:5-28.

35. Carter M. The landless workers movement and democracy in Brazil. Latin American Research Review 2011; 45 Special Issue:186-217.

36. Scopinho RA. Sobre cooperação e cooperativas em assentamentos rurais. Psicol Soc 2007; 19:84-94

37. Elias D. Agronegócio e desigualdades socioespaciais. In: Elias D, Pequeo R, organizadores. Difusão do agronegócio e novas dinâmicas socioespaciais. Fortaleza: Banco do Nordeste do Brasil; 2006. p 25-82.

38. Fontoura Junior EE, Souza KR, Renovato RD, Sales CM. Relações de saúde e trabalho em assentamento rural do MST na região de fronteira Brasil-Paraguai. Trab Educ Saúde 2011; 3:379-97.

39. Scopinho RA. Condições de vida e saúde do trabalhador em assentamento rural. Ciênc Saúde Coletiva 2010; 15 Suppl 1:1575-84

40. Barcelos SB. A formação do discurso da agroecologia no MST [Dissertação de Mestrado]. Rio de Janeiro: Instituto de Ciências Humanas e Sociais Universidade Federal Rural do Rio de Janeiro; 2010.

41. Nouroudine A. Como conhecer o trabalho quando o trabalho não é mais o trabalho? Trab Educ Saúde 2011; 9:69-83.
42. Movimento dos Trabalhadores Rurais Sem Terra Relatos de experiências em saúde. Brasília: Coletivo Nacional de Saúde; 2005.

43. Movimento dos Trabalhadores Rurais Sem Terra Cartilha: conhecer, organizar, mobilizar. Brasília: Movimento dos Trabalhadores Rurais Sem Terra; 1998.

44. Movimento dos Trabalhadores Rurais Sem Terra. O funcionamento das brigadas do MST. São Paulo: Setor de Formação; 2005.

45. Brito J. Saúde do trabalhador: reflexões a partir da abordagem ergológica. In: Figueiredo M, Athayde M, Brito J, Alvarez D, organizadores. Labirintos do trabalho: interrogações e olhares sobre o trabalho vivo. Rio de Janeiro: DP\&A; 2004. p. 91-114.

46. Schwartz Y. Ergonomia, filosofia e extraterritorialidade. In: Daniellou F, oraganizador. Ergonomia em busca de seus princípios: debates epistemológicos. São Paulo: Editora Edgard Blücher; 2004. p. $142-80$.

47. Hennington EA. Gestão dos processos de trabalho e humanização em saúde: reflexões a partir da ergologia. Rev Saúde Pública 2008; 42:555-61.

Recebido em 17/Jul/2012

Versão final reapresentada em 12/Mar/2013

Aprovado em 26/Mar/2013 